19. Кравцева А.П., Петрова А.Б., Савицкая К.С., Кавеленова Л.М., Кузнецов А.А., Антипенко М.И. Особенности сезонной динамики зольного компонента в листьях различных сортов груши и земляники садовой // Вестник молодых ученых и специалистов Самарского гос. университета. 2014. № 2. С. 31-36.
20. Кавеленова Л.М., Кравцева А.П., Трубников А.М., Янков Н.В. К возможностям оценки функциональной активности листовых пластинок древесных растений // Известия Самарского научного центра Российской академии наук. 2013. Т. 15, № 3 (7). С. 2333-2336.

\title{
CONCERNING THE PROSPECTS OF QUANTITATIVE VALUING OF LEAF SURFACE FUNCTIONAL ACTIVITY FOR DIFFERENT PLANTS
}

(C) 2016

L.M. Kavelenova, doctor of biological sciences, head of Ecology, Botany and Nature Protection Department

A.B. Petrova, postgraduate student of Ecology, Botany and Nature Protection Department

A.M. Trubnikov, postgraduate student of Ecology, Botany and Nature Protection Department

N.V. Yankov, postgraduate student of Ecology, Botany and Nature Protection Department

K.A. Savitskaya, student of Biology Faculty

A.P. Kravtseva, postgraduate student of Ecology, Botany and Nature Protection Department

Samara National Research University, Samara (Russia)

M.I. Antipenko, candidate of agricultural sciences, senior researcher

A.A. Kuznetsov, candidate of agricultural sciences, senior researcher

Research Institute of Horticulture and Medicinal Plants «Zhiguliovskye Sady», Samara (Russia)

Abstract. The following paper discusses the problem of ecophysiological indicators evaluation and comparison for trees foliage formed in dynamic environment conditions. In addition to the already used methods of leaf parameters screening we propose to use one more indicator, characterizing foliage functional activity. In these aims, after performing some analytical procedures with leaf mass samples, some calculations must be made allowing to determine the quantity of active components (for instance, photosynthetic pigments, ash, etc.), per unit of leaf surface area.

The prospects of proposing parameter use seem to be fruitful for a variety of purposes, including: - analysis of the seasonal dynamics features of the leaf metabolic activity; - comparison of ecophysiological characteristics of various plants (species and varieties, local and introduced objects); - reactions to stress factors, a comparison of various objects in resistance to stress.

The article bases on the original data relating to the vegetation period of 2013-2015. The leaf mass samples were taken: for wild tree or shrub species - in the Krasnosamarsky forests, for fruit crops - in the gardens of Samara regional research institute «Zhiguliovskye Sady», for exotic tree and shrub species - in the dendrarium of the Botanical Garden of the Samara University. The leaf samples treatment mass procedure was performed according to the algorithm previously developed. In general, all aforementioned objects demonstrated more smooth dynamics of pigments component content per surface area unit than per mass unit. This situation seems to be connected with age-related changes of the leaf blades, saturated during the vegetative period with a certain amount of «ballast» substances or osmotically active compounds during stress periods, and so forth. The screening of photosynthetic surface unit quality allows us to note that the plants maintain a certain level of the metabolic activity of the leaf during variable weather conditions, producing a rapid «adjustment» pool of photosynthetic pigments on the basis of specific and varietal characteristics of their ecological plasticity.

Keywords: woody plants; photosynthetic pigments; leaf parameters screening; Krasnosamarsky forest; Research Institute of Horticulture and Medicinal Plants «Zhiguliovskye Sady»; pear and strawberry varieties; exotic species; Botanical Garden of Samara University; vegetative season; leaf mass per area unit.

УДК 332.1/ 504.03

\section{ЭКОМОДЕРНИЗАЦИЯ БАССЕЙНОВ КРУПНЫХ РЕК КАК ФАКТОР УСТОЙЧИВОГО РАЗВИТИЯ ТЕРРИТОРИИ (НА ПРИМЕРЕ ВОЛЖСКОГО БАССЕЙНА И БАССЕЙНА РЕКИ ЯНЦЗЫ)}

(C) 2016

Г.Э. Кудинова, кандидат экономических наук, доцент, старший научный сотрудник, заведующий группой экономики природопользования Г.С. Розенберг, доктор биологических наук, профессор, член-корреспондент РАН, заведующий лабораторией моделирования и управления экосистемами, директор

Н.В. Костина, кандидат биологических наук, старший научный сотрудник лаборатории моделирования и управления экосистемами

А.Г. Розенберг, кандидат биологических наук,

младший научный сотрудник группы экономики природопользования

Институт экологии Волжского бассейна РАН, Тольятти (Россия)

Аннотация. В статье обсуждаются основные понятия экологической модернизации. Рассмотрена экологическая модернизация в России, проведено сравнение хода экологической модернизации в России и Китайской 
Кудинова Г.Э., Розенберг Г.С., Костина Н.В., Розенберг А.Г.

народной республики на примере Волжского бассейна и бассейна реки Янцзы. Приводятся кластерный анализ территории Волжского бассейна по отношению к устойчивому развитию территорий и почему для дальнейшего устойчивого развития во всех областях экономической и социальной сферы необходимо соблюдать принципы экологической модернизации. Устойчивое развитие Волжского бассейна во многом определяет устойчивое развитие России в целом и обуславливает необходимость экологической модернизации на данной территории. Приведены основные практические шаги по экомодернизации Российской экономики.

Ключевые слова: экологическая модернизация; устойчивое развитие; социальная экология; экологические проблемы; Волжский бассейн; экологизация экономики; кластерный анализ территорий; Китайская Народная Республика; Российская Федерация.

Разлад между Россией и Западом из-за украинского кризиса 2014 г. имеет далеко идущие геополитические последствия. Россия вернулась к своему традиционному положению евразийской державы, занимающей место между Востоком и Западом, и, столкнувшись с политическим и экономическим давлением США и Европы, склоняется в сторону Китая. Отношения России и Китая имеют ключевое значение в российской внешней политике. Китай в нынешних условиях является главным партнёром и союзником России - как в военно-политическом, так и в экономическом плане [1]. На смену концепции «Большой Европы» от Лиссабона до Владивостока, состоящей из ЕС и возглавляемого Россией Евразийского экономического союза, приходит «Большая Азия» от Шанхая до Петербурга.

В чем заключается общность стратегических интересов Китая и России? Обе эти страны в данный момент еще не преодолели индустриальную стадию своего развития, а, следовательно, не перешли в постинудстриальное общество. По этой причине и та и другая страна нуждается в благоприятных условиях для развития, в мирной окружающей обстановке, в благоприятной экологической среде, чтобы сосредоточиться на проблемах созидательного строительства и экономического развития [2].

Следовательно, и России и Китаю для дальнейшего устойчивого развития во всех областях экономической и социальной сферы, необходимо соблюдать принципы экологической модернизации.

Экологическая (а в более широком смысле, социально-экологическая) модернизация - явление многоаспектное. «В современном мире уже нет отдельно "человека" и "природы": человек экологизирован, природа социализирована. Отсюда следует, что меры по сохранению и улучшению состояния среды обитания есть необходимый компонент "пакета" мер развития. Сегодня "экологический фактор" - растущий по значению ограничитель любых усилий по модернизации производства и его инфраструктуры, так как всякое превышение несущей способности локальных экосистем и биосферы в целом возвращается бумерангом обществу в форме сокращения рождаемости, роста заболеваемости и смертности, роста миграционных расходов и т.д.». [3]

Важно отметить: природа не нуждается в модернизации - она нуждается в заботе и в бережном отнотении к ней!

А для этого необходимо модернизировать не только то, что создано человеком и непосредственно влияет на окружающую среду, но и само отношение Человека к Природе: модернизация должна начаться с нашего сознания и мировосприятия и только после этого она перекинется на все сферы нашей жизни. И как тут не вспомнить классические слова персонажа произведения Михаила Булгакова «Собачье сердце» Филиппа Филипповича Преображенского...

Еще в 80-х годах XX в. в странах Западной Европы и США экологическая модернизация была объектом изучения небольшой группы ученых, которые исследовали социальные процессы в области охраны природы и рационального природопользования. Позже интерес к этой проблеме возрос и послужил широкой основной научной дискуссии. А уже в XXI в. тема экологической модернизации вышла за пределы только научных кругов (социальной экологии) и стала частью более широкого публичного обсуждения и даже вошла в государственные планы.

Согласимся с профессорами И.П. Кулясовы и Ч. Хэ [4], которые считают, что на данный момент нет единого определения «экологической модернизации», а можно выделить лишь четыре «смысловых слоя»:

- экологическая модернизация - теоретическая основа экосоциологии (социологическая интерпретация экологических реформ);

- экологическая модернизация - новая модель понимания и анализа технологически интенсивной экологической политики;

- экологическая модернизация - качественная модель отражения прогресса развитых стран в экологических и экономических реформах (начиная с 1980-х годов);

- экологическая модернизация - теория социальных перемен, описывающих экономические и социальные изменения, в основе которых лежит «экологический сигнал» (теория, нацеленная на развитие без враждебного отношения к природе).

Согласно концепции экомодернизации, экономические и экологические интересы должны стать взаимозависимыми, взаимодополняющими и неотделимыми друг от друга.

Сущностью данного процесса является «экономизация экологии» и наоборот - «экологизация экономики», то есть превращение экологических ограничителей в источники получения дополнительной прибыли, например за счет экономии сырья и материалов, расширения спроса на экологически чистые или произведенные экологически чистым способом товары.

Среди общетеоретических представлений об экологической модернизации профессор Хэ формулирует шесть основных выводов:

- экологическая модернизация является непреклонной исторической тенденцией;

- экологическая модернизация не будет легкой;

- экологическая модернизация требует инноваций и обучения;

- экологическая модернизация требует координации в рамках страны;

- экологическая модернизация требует международного сотрудничества; 
- нет никакой наилучшей модели экологической модернизации.

Последний вывод особенно интересен для выбора генерального направления отечественной экологической модернизации. В связи с чем, опыт экологической модернизации Китая может быть полезен и нам.

На рис. 1 представлен, в какой-то степени, образный пример, демонстрирующий характерные черты четырех областей долины главной китайской реки Янцзы (третья в мире по протяженности и полноводности) и четырех стадий эволюции общества $[5 ; 6 ; 7 ; 8]$.

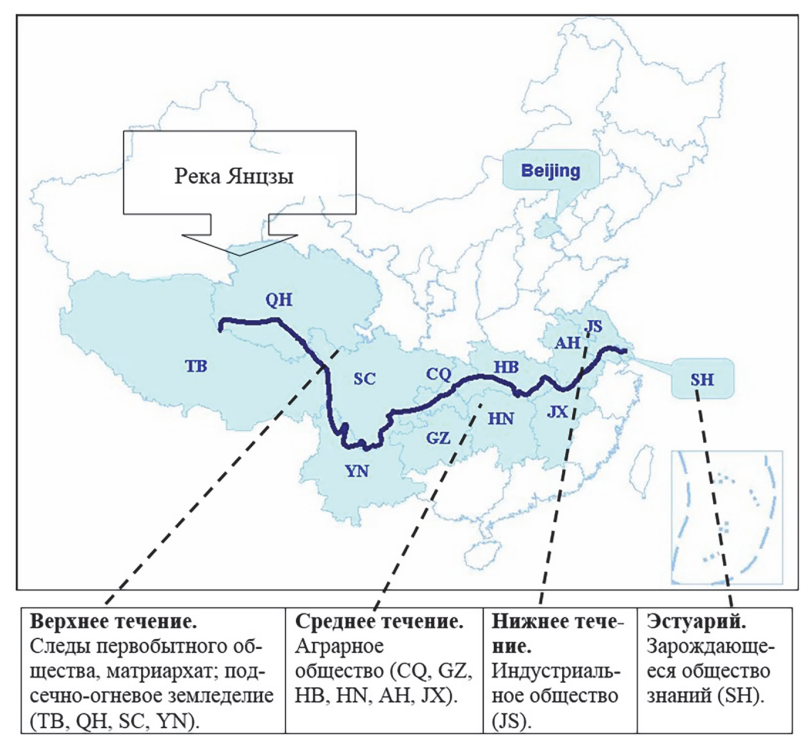

Рисунок 1 - Районирование бассейна р. Янцзы по параметрам экомодернизации (данные 2006 г.)

В табл. 1 приведены результаты сравнительного анализа крупнейших рек Европы и Азии (см. также рис. 1 и 2).

Таблица 1 - Некоторые данные по рекам Волга и Янцзы

\begin{tabular}{|l|c|c|}
\hline \multicolumn{1}{|c|}{ Показатель } & Волга & Янцзы \\
\hline $\begin{array}{l}\text { Протяженность } \\
\text { (км) }\end{array}$ & 3530 & 6300 \\
\hline $\begin{array}{l}\text { Площадь бассей- } \\
\text { на (млн. км })^{2}\end{array}$ & 1,36 & 1,81 \\
\hline $\begin{array}{l}\text { Количество } \\
\text { регионов }\end{array}$ & $\begin{array}{c}39+2 \text { (Казахстан); } \\
\text { основных (более } 80 \% \\
\text { территории) - 24 }\end{array}$ & 12 \\
\hline $\begin{array}{l}\text { Население } \\
\text { (млн. чел.) }\end{array}$ & 56,0 & 517,2 \\
\hline
\end{tabular}

На рис. 1 и 2 представлены результаты районирования провинций бассейна р. Янцзы и Волжского бассейна в пространстве экономических (ВВП на душу населения, структура производства [сельское хозяйство, промышленность, услуги] и структура занятости [сельское хозяйство, промышленность, услуги]) и социальных факторов (уровень урбанизации, ожидаемая продолжительность жизни, уровень детской смертности, доля населения с высшим образованием).

Проведенный в целях районирования кластерный анализ для территории Волжского бассейна («одиночный подход»; рис. 2), позволил выделить три класса, которые, правда, в этом варианте районирования не интерпретируются, подобно бассейну Янцзы, на оси «первобытное общество - общество знаний». А вот районирование в варианте «смешанного подхода» (бассейны Волги и Янцзы) позволяет увидеть «положение» территорий Волжского бассейна при такой ординации (см. рис. 3).

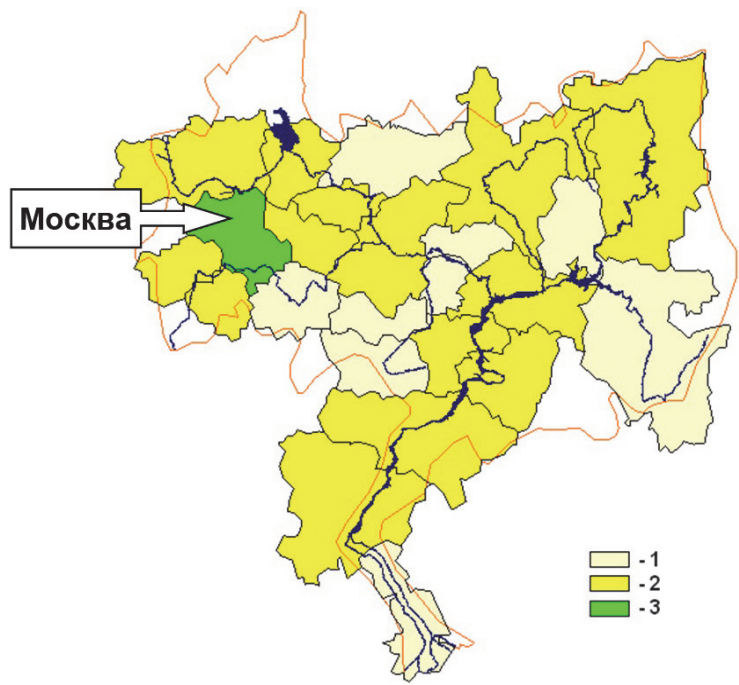

Рисунок 2 - Районирование Волжского бассейна по параметрам экомодернизации (данные 2006 г.).

1. ближе к аграрному обществу;

2. ближе к индустриальному обществу; 3. ближе к обществу знаний

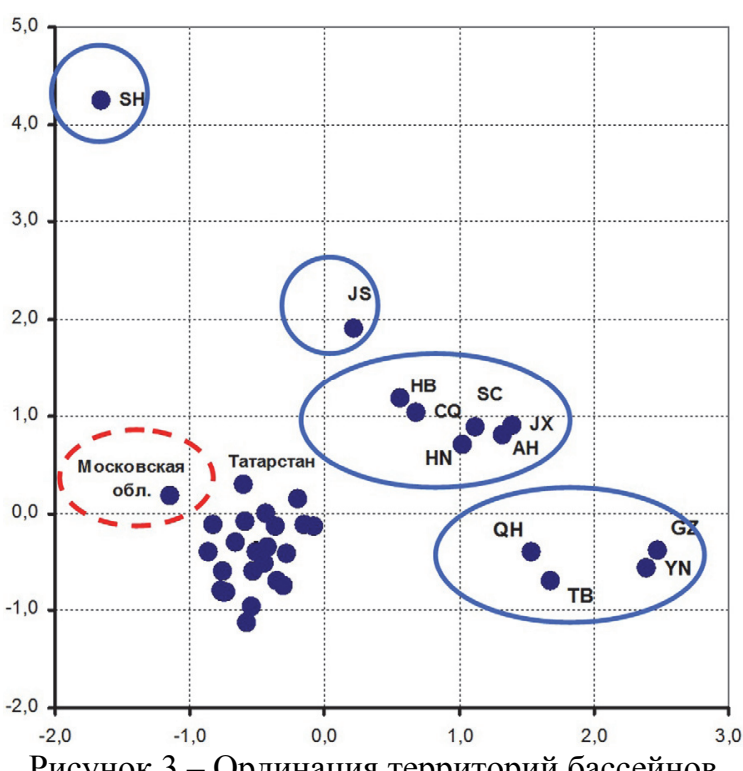

Рисунок 3 - Ординация территорий бассейнов

рек Янцзы и Волга в факторном пространстве («смешанный подход»)

Легко убедиться, что провинции бассейна p. Янцзы «выстроились», практически, вдоль прямой и хорошо демонстрируют разбиение на четыре типа модернизационных обществ. Территории Волжского бассейна «сбились в кучу» и относятся ко второму и третьему (сюда попали Московская область, Татарстан, Самарская, Саратовская и Ярославская области) типу обществ. Заметим, что если добавить в качестве отдельной территории субъект федерации г. Москву, то, вполне возможно, Москва (может быть вместе с Московской областью) выделится в отдельную группу территорий - общества знаний.

Волжский бассейн продолжает оставаться одним из наиболее напряженных по экологической обстановке в России, что и делает актуальной проблему пе- 
Кудинова Г.Э., Розенберг Г.С., Костина Н.В., Розенберг А.Г.

рехода региона на путь экологической модернизации при обеспечении устойчивого развития страны. Устойчивое развитие Волжского бассейна во многом определяет устойчивое развитие России в целом и обуславливает необходимость экомодернизации на данной территории.

Решение экологических проблем в России требует в первую очередь утверждения единого документа, определяющего содержание федеральной политики в области экологического развития страны (стратегия «зелёного роста»), предусматривающей интеграцию социально-экономического и экологического развития.

Основные практические шаги по экомодернизации Российской экономики (составлено по [9; 10]):

1. Создать концепцию перехода России к экологической модернизации при активном участии Правительства, частного сектора, научных учреждений, общественных организаций и международных институтов.

2. В рамках концепции целесообразно разработать программы по каждому из приоритетных направлений экологической модернизации.

3. Создать нормативно-правовые основы перехода России к экологической модернизации.

4. Включить в число приоритетных направлений государственных инвестиций и расходов на экомодернизацию экономики.

5. Способствовать ограничению государственных расходов в областях, приводящих к истощению природного капитала.

6. Содействовать реализации пилотных проектов по каждому из направлений экологической модернизации.

7. Стимулировать инвестиционные вложения в образование, обучение и повышение квалификации в целях подготовки рабочей силы при экологической модернизации экономики.

8. Обеспечить укрепление международного сотрудничества в сфере экологической модернизации экономики.

В будущем проблемы сохранения окружающей природной среды, обеспечения устойчивого развития и сохранения нашей планеты для последующих поко- лений все же решатся путем распространения экомодернизации через «озеленение» экономики в регионах России, странах бывшего СССР и третьего мира.

\section{СПИСОК ЛИТЕРАТУРЫ:}

1. Справочник патриота [Электронный ресурс] // http://ruxpert.ru.

2. Титоренко М. Взаимоотношение России и Китая [Электронный ресурс] // http://ru.journal-neo.org/ 2014/ 03/07/vzaimootnosheniya-kitaya-i-rossii.

3. Яницкий О.Н. Экомодернизация России: проблемы, концепции, решения // История и современность. 2008. № 2, сентябрь. С. 95.

4. Кулясов И.П. Экологическая модернизация: теория и практика. СПб: НИИХ СПбГУ, 2004. 154 с.

5. Кудинова Г.Э., Розенберг Г.С. Сравнительный анализ экологической модернизации в Китае и России // Изв. СНЦ РАН. 2012. Т. 14, № 1(9). С. 2423-2431.

6. Кудинова Г.Э., Розенберг Г.С. Экологические аспекты модернизации по-китайски и по-нашему (Обзорный доклад о модернизации в мире и Китае [20012010] / под ред. Ч. Хэ и Н.И. Лапина. - М.: Весь Мир, 2011. - 256 с.) // Самарская Лука: проблемы региональной и глобальной экологии: Бюл. 2012. Т. 21, № 4. С. 20-33.

7. Кудинова Г.Э., Розенберг А.Г., Розенберг Г.С. Экологическая модернизация: становление, современное состояние и перспективы // Самарская Лука: проблемы региональной и глобальной экологии: Бюл. 2013. T. 22, № 2. С. 5-26.

8. Розенберг Г.С., Костина Н.В., Кудинова Г.Э., Розенберг А.Г. Экологическая модернизация: бассейновый подход на примере крупнейших рек Азии и Европы // Вестн. Самар. гос. эконом. ун-та. 2014. Спецвыпуск. С. 25-34.

9. Живая планета. Биоразнообразие, биоемкость и развитие. Гл. 3: Зелёная экономика. Доклад Всемирного фонда природы о Живой планете. 2010. 10 с.

10. Сычева И.Н. «Зелёная» экономика - устойчивое развитие экономики // Вестник Алтайской науки. 2013. № 2-2. C 188-189.

\section{ECOLOGICAL MODERNIZATION OF LARGE RIVER BASINS AS A FACTOR OF SUSTAINABLE DEVELOPMENT OF THE TERRITORY (FOR EXAMPLE, THE VOLGA RIVER BASIN AND YANGTZE RIVER BASIN)}

(C) 2016

G.E. Kudinova, candidate of economical sciences, associate professor, senior researcher, head of Environmental Economics Group

G.S. Rozenberg, doctor of biological sciences, professor, corresponding member of the Russian Academy of Sciences, head of Modeling and Management of Ecosystems Laboratory, director

N.V. Kostina, candidate of biological sciences,

senior researcher of Modeling and Management of Ecosystems Laboratory

A.G. Rozenberg, candidate of biological sciences, junior researcher of Environmental Economics Group Institute of Ecology of Volga River Basin of Russian Academy of Sciences, Togliatti (Russia)

Abstract. The paper discusses the basic concepts of ecological modernization. The process of ecological modernization in Russia is examined. One compared the progress of ecological modernization in Russia with one in the People's Republic of China on the example of the Volga basin and the basin of the Yangtze River. Provides cluster analysis of the Volga basin territory in relation to the sustainable development of the territories and why for further sustainable development in all areas of economic and social sphere, it is necessary to observe the principles of ecological modernization. Sustainable development of the Volga river basin largely determines the sustainable development towards ecological modernization in the area. The main practical steps to ecomodernization of Russian economy are suggested.

Keywords: ecological modernization; sustainable development; social ecology; environmental problems; Volga River basin; greening of economy; cluster analysis of territories; China; Russian Federation. 